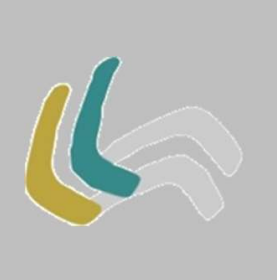

\title{
MEMÓRIA(S) EM LA DISTANCIA QUE NOS SEPARA
}

\section{MEMORY(S) IN LA DISTANCIA QUE NOS SEPARA}

\author{
Adriana Binati Martinez ${ }^{1}$ \\ Universidade Estadual do Centro-Oeste
}

Resumo: O presente artigo apresenta uma leitura da construção da(s) memória(s) no romance $L a$ distancia que nos separa (2015), de Renato Cisneros. O jornalista e autor peruano alicerça a narrativa em liames tênues e porosos entre biografia, ficção e história abertos a múltiplos signos de compreensão. Nesta proposta analítica lemos a obra como autoficção onde o narrador desenterra a figura paterna Luis Federico Cisneros Vizquerra - mais conhecido como El Gaucho Cisneros, general da División del Ejército Militar del Perú - para contestar a uma obsessão: a busca da identidade. Regressar ao passado apresenta-se como uma forma de ler o presente e a si próprio. Apoiados em AÍNSA (2012), RICOUER (2010), SARLO (2007), interpretamos que o entendimento da memória é engendrada na ideia de uma construção permanente impugnando qualquer versão acabada dessas vivências, identidades e escrita narrada.

Palavras-chave: Memórias; Narrativa peruana contemporânea; A figura do pai; Identidades.

1 Endereço eletrônico: abmartinez08@gmail.com. 


\begin{abstract}
This article presents a reading of the construction of memory (or memories) in the novel La Distancia que nos Separa (2015), by Renato Cisneros. The Peruvian journalist and author bases the narrative on tenuous and porous links between biography, fiction and history, all open to the multiple signs of understanding. In this analytical proposal, we read the work as self-fiction, where the narrator unearths the father figure of Luís Federico Cisneros Vizquerra - better known as El Gaucho Cisneros, general of the División del Ejército Militar del Perú -, to challenge an obsession: the search for identity. Returning to the past presents itself as a way of reading the present and oneself. Supported by AÍNSA (2012), RICOUER (2010), SARLO (2007), we interpret that the understanding of 'memory', in the aforementioned work, is engendered on an idea of permanent construction, challenging any finished version of these experiences, identities and narrated writing.
\end{abstract}

Keywords: Memories; Contemporary Peruvian narrative; Father figure; Identity.

\title{
INTRODUÇÃO: EM BUSCA DO PAI
}

A figura do pai parece ser uma busca ininterrupta nos romances $\mathrm{La}$ distancia que nos separa (2015) e Algún día te mostraré el desierto (2019) de Renato Cisneros $(1976)^{2}$. No primeiro o enredo se volta para a tentativa do narrador em traçar a biografia do pai, que foi general da División del Ejército del Perú, Luis Federico Cisneros Vizquerra, mais conhecido como El Gaucho Cisnero; e, no segundo, que remete a um diário de viagem, há uma autoanálise da paternidade em que o narrador se dirige à filha Julieta. Em ambas obras, o tema se apresenta de modo complexo e conflitante em relação a identidade do filho, ou seja, nas narrativas há paralelismos nestas (re)construções identitárias.

Apesar dessa retomada e, pode-se dizer, continuidade da temática do pai e do filho na produção narrativa de Renato Cisneros, este estudo se centra na leitura do primeiro romance. Tal escolha se deve ao fato que é uma obra que se constitui por elementos narrativos que, numa autoavaliação explicitada pelo narrador, não se trata de uma mera biografia do pai, mas antes de uma reflexão acerca desse sujeito e, por consequência, de si mesmo (narrador).

2 Igualmente publicou obras de poemas Ritual de los prójimos (1998), Máquina Fantasma (2001), Nuevos Poemas Italianos (2007), e os romances Nunca confíes en mí (2011), Raro (2012) e Dejarás la tierra (2019). 
Em La distancia que nos separa a escrita sobre o pai morto está tecida por ausências, lacunas e tensões não resolvidas no passado narrado e, tampouco, no tempo presente do romance. Entretanto, é justamente nesta arquitetura verbal que o narrador encontra interpretações viáveis para relacionar-se com o sujeito que foi vitimado por um câncer de próstata e, desde 15 de julho de 1995, com sua privação permanente.

A (re)significação destas identidades se alicerça no relato memorialístico do narrador e de outras vozes que busca para traçar o passado do pai (incluindo documentos arquivados no exército), como também no desenho da árvore genealógica que tem como fundadores a tataravó Nicolasa Cisneros e sua relação extraconjugal com Gregorio Cartagena, bispo de Huánco, sierra do Peru, nos anos prévios e posteriores a Independência do país no século XIX. Roberto Benjamín é o suposto marido, sujeito fictício e fantasmal criado por Nicolasa Cisneros para dar oficialidade ao nascimento do filho Luis Benjamín Cisneros. O relato inicial da família apresenta a orfandade paterna que será uma cicatriz nas gerações posteriores, relegando estes sujeitos ao estigma de bastardos ${ }^{3}$.

De imediato, esta origem aponta para dois signos constantes da família na intriga do romance: as conturbadas relações extraoficiais e as experiências passadas privadas imbricadas com a história coletiva, também marcada pelo deslocamento forçado do exílio (Panamá, Argentina/Buenos Aires e uma passagem pela França/Paris) e nos heterogêneos impactos causados no regresso

\footnotetext{
3 Ainda que não seja objeto desta leitura, é pertinente argumentar que estas caracterizações identitárias colocam estes personagens em uma condição de inferioridade em relação aos outros que constituem a família oficializada pelas leis civis, como é o matrimônio institucionalizado pela igreja. Neste sentido, guardada as devidas proporções, o estigma do bastardo também poderia ser lido aproximado com o pária, no sentido deste nascimento "ilegítimo" estabelecer uma barreira invisível que marca este sujeito "[...] como membro de uma categoria inferior", conferindo-lhe "[...] ao mesmo tempo, uma alta visibilidade social que o impede de se amalgamar a seus vizinhos. Estreitamente ligada à sua inferioridade, sua alta visibilidade como membro deste ou daquele grupo faz parecer abusiva e ilegítima qualquer tentativa de sua parte de exercer os direitos (por exemplo, a presunção da inocência) que ele compartilha legalmente com o restante da população (legítima)" (VARIKAS, 2014, p. 112-113, grifo da obra).
} 
à terra pátria: “Meu bisavô era um bastardo. Meu avô um exilado. Meu pai um estrangeiro. Três homens ilegítimos e sem raízes"4 (CISNEROS, 2015, VII, p. 01, tradução livre nossa).

Na esfera privada, o pai do narrador é filho de Fernán Cisneros e da amante Esperanza Visquerra, nascido na Argentina e criado no país até o início da vida adulta, sendo que esta origem e formação militar lhe renderam o nome El Gaucho. Já no campo público, coletivo e histórico trata-se do controverso General das Forças Armadas, Ministro del Interior e de Guerra del Perú nos governos de Francisco Morales Bermúdez (1975-1980) e de Fernando Belaúde Terry (1980-1985), ou seja, durante o Conflito Armado Interno (1980-2000)5 no país. Para além disto, foi companheiro de Jorge Rafael Videla, Leopoldo Galtieri e de outros membros do governo militar argentino. Publicamente foi admirador de Henry Kissinger (secretário de Estados Unidos) e do general Augusto Pinochet. A frente do combate ao conflito armado interno, foi o responsável por coordenar as operações do Plan Cóndor e promoveu ações contra os grupos Partido Comunista do Perú - Sendero Luminoso (PCP-SL) e Movimiento Revolucionario Túpac Amaru (MRTA).

\footnotetext{
4 Texto original: "Mi bisabuelo era un bastardo. Mi abuelo un deportado. Mi padre un extranjero. Tres hombres ilegítimos y desarraigados" (CISNEROS, 2015, VII, p. 01).

5 De acordo com Lucero de Vivanco "Este es el conflicto armado más prolongado y el que más impacto ha tenido en el Perú, en toda su historia republicana. Miles de testimonios registrados por la Comisión de la Verdad y Reconciliación (CRV), una gran cantidad de material visual y periodístico, y centenares de publicaciones - tanto académicas como literarias - dan cuenta de la violencia extrema que, en veinte años, dejó cerca de 70.000 muertos y un territorio moral, social, económica y políticamente devastado" (VIVANCO, 2013, p. 5718).

6 Para diversos estudiosos, entre eles Norberto Barreto Velásquez e J. Patrice McSherry, à lista de países que participaram da Operação Cóndor deve-se acrescentar o Peru e o Equador. De modo geral, entre os anos de 1970 e 1980, nos países latino-americanos houve uma "alianza entre las elites y los militares buscaba retener el control del Estado, amenazado por el avance de los grupos que demandaban cambios estructurales en los ámbitos político y socioeconómico. En otras palabras, tanto las elites como los militares latinoamericanos querían conservar su posición social y sus privilegios, evitando a toda costa una «redistribución de los recursos socioeconómicos». El apoyo estadounidense fue el resultado de la doctrina anticomunista de seguridad nacional adoptada por el gobierno norteamericano durante la Guerra Fría" (BARRETO VELÀZQUEZ, 2013, p. 173, grifos do texto).
} 
Em entrevista cedida a Angelo Atanasio, para a BBC Mundo, em 2018, o jornalista e escritor peruano responde sobre a difícil tarefa de abordar a figura paterna que também se constitui um personagem público problemático na história recente peruana:

Por um lado é um vilão, mas ao mesmo tempo é um herói para outros setores do país. É um homem sentimental e também um homem rude. Sem dúvidas é um homem autoritário, mas que tem fraquezas internas que evitou mostrar. O que fiz foi escrever sobre ele como se não tivesse sido meu pai, como se fosse um personagem realizado com minhas memórias, com minhas especulações literárias, com os testemunhos que recolhi. Não imaginá-lo como o homem com quem convivi por 18 anos, mas como um personagem como finalmente se constituía. ${ }^{7}$ (ATANASIO, 2018, tradução livre nossa)

Apesar desta visão de Renato Cisneros em abordar a figura do pai como um personagem ficcional, interpretamos que sua narrativa dialogaria de perto com algumas tendências reconhecíveis da literatura hispano-americana contemporânea dos últimos decênios, como, por exemplo, a memória familiar que se confronta o discurso oficial da história8. Muitas das vezes tal discurso é lido com desconfiança nestas obras e, quiçá, este rumo nada inédito na literatura9 corresponderia a uma reflexão sobre o sentimento de identidade que, segundo Fernando Aínsa, pode ser volúvel e móvel respondendo a múltiplas ramificações. Para o ensaísta, autor e crítico literário é possível delinear duas formas de identidade que coexistem criticamente: “[...] uma que se fecha sobre si mesma e

\footnotetext{
7 Texto original: “Por un lado es un villano pero también está considerado un héroe por parte de un sector del país. Es un hombre sentimental pero también es un hombre rudo. Es un hombre sin duda autoritario pero que tiene sus flaquezas internas, que evita mostrar. Lo que hice fue escribir sobre él como si no hubiera sido mi padre, como si fuese un personaje hecho con mis recuerdos, con mis especulaciones literarias, con los testimonios que fui recogiendo. No imaginarlo como el hombre con quien conviví 18 años sino como el personaje que finalmente era".

8 Como exemplo cito Árbol de Familia (2010), de María Rosa Lojo, El cuerpo en que nací (2011), de Guadalupe Nettel, Un comunista en calzoncillos (2013), de Cláudia Piñeiro, e Una vez Argentina (2014), de Andrés Neuman.

9 Dentre tantas publicações literárias ocidentais, menciono Carta ao pai (1952), de Franz Kafka.
} 
insiste na permanência e outra que se alicerça na progressiva integração do novo"10 (AÍNSA, 2012, p. 162, tradução livre nossa).

Em La distancia que nos separa, nossa proposta de leitura é que a reflexão identitária se reconfigura desde o processo da escrita e das múltiplas vozes que o narrador interpela sobre o pai que, igualmente, promovem uma constante releitura subjetiva sobre Luis Federico Cisneros Vizquerra (indivíduo), o pai (relação familiar), El Gaucho (controversa figura pública) e o próprio narrador:

[...] Se consigo entender quem ele foi antes do meu nascimento, talvez poderia entender quem sou agora que ele está morto. Nestas duas perguntas gigantescas se alicerçam o enigma obsessivo: Quem era ele antes de mim. Quem sou eu depois dele. O meu único objetivo é este: reunir e mediar a estes homens. ${ }^{11}$ (CISNEROS, 2015, IV, p. 04, tradução livre nossa)

No romance o passado e a identidade não estão petrificadas, ou seja, se apresentam como construções permanentes de sentidos e de dúvidas porque são oriundas de subjetividades múltiplas e móveis no tempo e no espaço. E, num sentido subjacente a esta arquitetura da trama, o romance explicita que a(s) memória(s), a interpretação dada ao passado e as expectativas assinaladas no tempo presente da escrita e do futuro das personagens estão sob a égide da linguagem. Em Tempo e narrativa, Paul Ricouer propõe que:

[...] Narramos coisas que consideramos verdadeiras e predizemos acontecimentos que ocorrem tal como os antecipamos. Portanto, é ainda a linguagem, assim como a experiência e a ação que articula, que aguentam firme contra o assalto dos céticos. (RICOUER, 2010, p. 21, grifos do autor)

10 Texto original: "[...] una que se cierra sobre sí misma e insiste en la permanencia y otra se va firmando por la progresiva integración de lo nuevo" (AÍNSA, 2012, p. 162).

11 Texto original: [...] Si consigo entender quién fue él antes que yo naciera, quizá podré entender quién soy ahora que está muerto. Es en esas dos titánicas preguntas que se sostiene el enigma que me obsesiona: Quién era él antes de mí. Quién soy yo después de él. Ese es mi objetivo sumario: reunir a esos hombres intermedios" (CISNEROS, 2015, IV, p. 04). 
A noção de tempo e de seus acontecimentos são resultados de signos verbais que se valem de entendimentos permeados por subjetividades. A tênue linha entre o discurso da história e da ficção - que desde Arte Poética, de Aristóteles, tem sido debatida em distintos campos do saber, como o da literatura - na narrativa memorialística de Renato Cisneros se apresenta como linguagem e sob frequente recusa de definições de qualquer ordem:

Este é um romance sobre ele ou de alguém muito parecido com ele, escrito por mim ou por alguém muito parecido comigo. Um romance não biográfico. Não histórico. Não documental. Um romance consciente que a realidade ocorre somente uma vez e que qualquer reprodução que se realize dela está condenada a adulteração, a distorção, ao simulacro. ${ }^{12}$ (CISNEROS, 2015, I, p. 06, tradução livre nossa)

Esta interpretação realizada da própria escrita põe em questionamento alguns tópicos estruturantes do romance como a proximidade entre narrador e narrado apesar da intenção explicitada em distanciar-se do relato biográfico, histórico e documental. Como se sabe, um dos efeitos da narrativa em primeira pessoa é a eliminação do intermediário e a sensação de distanciamento com o narrado. Em La distancia que nos separa, a despeito da intenção do narrador em afastar-se do passado que relata, esse desejo não se cumpre. Tanto pela escolha da narração que apresenta, porque se assume como filho do Gaucho, como pelo fato que seu relato dialoga com a história nacional, com a biografia e com diversos documentos que investiga sobre o pai. Igualmente no romance, no que tange aos questionamentos arquitetônicos, se observa que há um entendimento que a ficção é uma interpretação da realidade e, desta forma, consiste em ser um simulacro verbal e subjetivo desta realidade narrada. Para o narrador Cisneros,

12 Texto original: "Es una novela acerca de él o de alguien muy parecido a él, escrita por mí o por alguien muy parecido a mí. Una novela no biográfica. No histórica. No documental. Una novela consciente de que la realidad ocurre una sola vez y que cualquier reproducción que se haga de ella está condenada a la adulteración, a la distorsión, al simulacro" (CISNEROS, 2015, I, p. 6). 
o único modo de conseguir a liberdade sobre a obsessão do pai (e em reconhecerse nesta identidade de filho, como estamos assinalando) é mediante o processo da escrita, ainda que de maneira difusa, contraditória e nunca completa, uma vez que a vida segue em curso.

Assim, podemos pensar que a busca do pai em La distancia que nos separa que, desde o princípio, exibe a construção do relato e de suas várias possibilidades de sentido como único caminho possível para compreender uma existência e dar algum significado a ela: “O que te desespera de imediato é não saber. [...] Por isso desenterra. Para saber se o conheceu a fundo ou se somente o viu passar"13 (CISNEROS, 2015, IV, p. 02). A partir deste horizonte de leitura do romance, o verbo desenterrar não diria respeito apenas à figura do pai, mas, sobretudo, a uma noção de mundo e de identidades que se estabelecem em intricados liames com o tempo, com o espaço e a própria linguagem.

\section{A(S) MEMÓRIA(S)}

O romance La distancia que nos separa está arquitetado em doze capítulos que não seguem uma ordem cronológica linear (do nascimento à morte, ou da morte ao nascimento), mas sim a alternada apresentação entre El Gaucho, a constituição da família Cisneros (árvore genealógica), a relação do narrador com o pai desde sua morte e a (re)construção do que pode ter sido sua vida. Esta organização da intriga solicitaria um leitor experiente às aberturas e múltiplos olhares do narrado, ou seja, um interlocutor disposto a estabelecer conexões sobre a narração, a sua constituição e a sua linguagem. A mencionada recusa do narrador em conceber sua obra como biografia, história ou documento estaria mais próxima de uma noção da autoficção, conforme anuncia na capa da edição:

13 Texto original: "Lo que te desesperas de pronto es no saber. [...] Por eso desentierras. Para saber si conociste a fondo o solo lo viste pasar" (CISNEROS, 2015, IV, p. 02). 
“Este é um romance de autoficção. Não é de interesse do autor que os fatos aqui narrados, assim como os personagens descritos a seguir, sejam julgados fora da literatura"14 (CISNEROS, 2015, tradução livre nossa).

Concebida sob a ambiguidade e limites porosos, a partir da obra de Phillipe Lejeune, autores como Serge Doubrovsky e Manuel Alberca propõem que a autoficção não se baseia na comprovação dos fatos verídicos e, tampouco, à matéria ficcional. Segundo Juliana Bevilacqua Maioli a respeito das discussões destes autores - com a qual corroboramos - a autoficção se instaura na:

[...] ambiguidade discursiva deliberada que, ao chamar atenção para o caráter ficcional do eu que narra, relega a um segundo plano a necessidade de se comprovar a autenticidade dos argumentos relatados, posto que o discurso - jogando simultaneamente com o real e o ficcional - transita livremente pelas fronteiras destas duas instâncias. (MAIOLI, 2020, p. 60)

Maioli adverte que as instâncias discursivas de narrador, autor e personagem solicitam um leitor capaz de ler estas nuances textuais e seus contornos fronteiriços e porosos. Ainda, segue a autora à luz dos referendados teóricos, nesta narrativa há uma permanente alteração na expectativa do leitor. Isto posto, é possível compreender La distancia que nos separa desde uma intepretação em que a (re)construção da memória do pai de Renato Cisneros (autor, personagem e narrador) seja uma autoficção apesar da proclamada rejeição deste sujeito discursivo em aceitar uma definição de gênero de sua escrita.

$\mathrm{A}(\mathrm{s})$ memória(s) no romance em estudo transita(m) entre o privado e o público, ou seja, entre estas distintas instâncias que descortinam a vida de Luis Federico Cisneros Vizquerra e El Gaucho Cisneros. Segundo o narrador:

14 Texto original: "[Este libro es una novela de autoficción. No es propósito del autor que los hechos aquí narrados, así como los personajes descritos a continuación, sean juzgados fuera de la literatura.]" (CISNEROS, 2015). 
[...] Tenho que desenterrar esses cadáveres empilhados, coloca-los à luz, dessecá-los, realizar uma autópsia geral. Não para saber o que os matou, mas para entender o que diabos os fez viver. ${ }^{15}$ (CISNEROS, 2015, IV, p. 05, tradução livre nossa)

Como se trata de uma autoficção - conforme estamos propondo - em que o formato não obedece a uma ordem cronológica da matéria narrada, desde o início o narrador elimina a possibilidade de ler este personagem paterno sem o signo da morte e de sua ausência na relação com o filho que o narra. A obsessão deste narrador consiste em narrar a sua vida, posto que esta seria a mola propulsora para encontrar algum significado na própria existência. Entretanto, nesta (re)construção memorialística realizada a partir de vários olhares - entre família, amigos, filhos de namoradas da juventude e documentos examinados no acervo do exército peruano - a empreitada da escrita e seu alcance preterido não se constituem facilmente:

[...] Aos poucos percebe que isto que te disseram durante anos a respeito da biografia de teu pai não te convence mais. Ou pior: entende que o que teu próprio pai dizia sobre sua biografia deixou de ser confiável. As mesmas versões que sempre soaram certas, suficientes, se tornam confusas, contraditórias, não estabelecem nexo, colidem ruidosamente com as ideias de que a morte de teu pai forjou no transcurso do tempo, e que uma vez reveladas consistem em ser uma ilha em que tu eres o náufrago. ${ }^{16}$ (CISNEROS, 2015, IV, p. 01, tradução livre nossa)

Para Beatriz Sarlo (2007, p. 10), o passado é sempre conflituoso. Isto porque, para além das discussões entre o íntimo e o público, entre o próximo e o

15 Texto original: "[...] Tengo que desenterrar esos cadáveres amontonados, sacarlos a la luz, diseccionarlos, practicarles una autopsia general. No para saber qué los mató, sino para entender qué diablos los hizo vivir" (CISNEROS, 2015, IV, p. 05).

16 Texto original: "[...] Poco a poco captas que eso que te han dicho durante años respecto de la biografía de tu padre no te convence más. O peor: captas que lo que tu propio padre decía sobre su biografía ha dejado de parecerte confiable. Las mismas versiones que siempre sonaron certeras, suficientes, se vuelven confusas, contradictorias, no encajan, colisionan estrepitosamente con las ideas de que la muerte de tu padre ha ido fraguado en tu interior en el transcurso del tiempo, y que una vez puestas de manifiesto son como un sólido islote que tiene a ti a su náufrago" (CISNEROS, 2015, IV, p. 01). 
distante, a memória pode constituir-se como um momento que se instaura no tempo presente sem que o sujeito queira ou não se lembre. Para a autora:

[...] O passado não se trata de um exercício de decisão, nem de inteligência; tampouco se constitui como um ato de vontade. A volta ao passado não é um momento libertador da memória, mas um advento, uma captura do presente. ${ }^{17}$ (SARLO, 2007, p. 10, tradução livre nossa)

Esta reflexão é pertinente porque, por mais que o narrador de La distancia que nos separe tenha um objetivo na escrita de seu romance, o fato que sua realização dependa da(s) memória(s), a sua concretude implica no reconhecimento do não controle de todos estes elementos discursivos e fugidios. Afinal, o passado e a experiência que cada um estabelece com ele neste transcurso de tempo, bem como sua noção de tempo presente, são instâncias subjetivas e apreensões sígnicas que cada um estabelece com as ações vividas. Interpretamos que a (re)construção da(s) memória(s) no romance de Renato Cisneros e as explicitações do seu processo de escrita encaram estas problemáticas sobre a narração e sobre sua linguagem: “Hoje não eres uma memória, mas o fragmento dela que me ataca como suaves rajadas. Que vem sobre mim"18 (CISNEROS, 2015, XII, p. 01, tradução livre nossa).

Sob este viés, o narrador argumenta que até mesmo a escolha pelo jornalismo (carreira que abandonou para dedicar-se a escrever o romance) teria sido inconsciente para esta empreitada em narrar a vida do pai. E, após o árduo trabalho que envolveu muitas entrevistas, leituras de documentos e construção de um nexo neste material coletado, igualmente reflete que a escolha por narrar literariamente se deve às alternativas em aberto sobre o narrado. Ou seja, para o

17 Texto original: “[...] Del pasado no se prescinde por el ejercicio de la decisión ni de la inteligencia; tampoco se lo convoca por un acto de la voluntad. El regreso del pasado no es siempre un momento liberador del recuerdo, sino un advenimiento, una captura del presente" (SARLO, 2007, p. 10).

18 Texto original: "Hoy no eres un recuerdo, sino el fragmento de un recuerdo que me ataca en suaves ráfagas. Que graniza sobre mí" (CISNEROS, 2015, XII, p. 01). 
narrador, as perguntas sobre a existência do pai e sobre sua relação com ele estão sujeitas a releituras e, por isto, a literatura é o discurso que mais se aproxima deste princípio libertador: "[...] A literatura penetra nos fatos que nos afetam. Eu necessitava isto: penetrar na memória do meu pai, intervir nela como um órgão que precisa de cirurgia"19 (CISNEROS, 2015, XII, p. 04, tradução livre nossa).

A relação do narrador com o pai em vida foi marcada por tensões e por um sistema educacional rígido. No relato memorialístico do romance, o narrador conta que o matrimônio de seu pai com sua mãe Cecília é fictício, ou seja, não chegaram a oficializar a união que se originou quando seu pai era casado oficialmente com Lucila e tinha família constituída. Assim, repetindo os atos de seus antepassados, seu pai abandona a família para viver seu relacionamento com a funcionária que conheceu em 1969 dentro da repartição do exército. Neste cenário, a vida pública e privada de Luis Federico Cisneros Vizquerra não se distingue, contudo, quando a relação extraconjugal se torna de conhecimento da instituição militar, toma a decisão de abandonar a família. Renato Cisneros, portanto, tem irmãos concebidos oficialmente (casamento do pai com Lucila) e extraoficialmente (como ele próprio).

Apesar do vínculo com os irmãos ser considerado saudável, pulsa em seu relato o sentimento de inadequação porque é fruto de um relacionamento extraconjugal. As palavras infidelidade, adultério, bigamia e ilegitimidade que designam estas relações não oficiais, por outro lado, segundo o narrador, também podem sinalizar para a opção pela paixão e pelo amor que triunfou sobre a ordem social estabelecida. Dito de outra forma, o narrador procura inverter o significado cultural e moral destes vocábulos como maneira de sair desta condição de inferioridade/ilegitimidade, ou seja, o relato memorialístico dá visibilidade a esta

19 Texto original: “[...] La literatura penetra en los hechos que nos afectan. Yo necesitaba eso: penetrar la memoria de mi padre, intervenirla como un órgano que precisa cirugía" (CISNEROS, 2015, XII, p. 04). 
condição que, convencionalmente, tampouco é anunciada às claras causando maiores problematizações nestes sujeitos:

[...] essas palavras, digo, são minha linhagem, são parte do meu legado direto, porque nomeiam aquilo que sou, que me constituem sem que eu tenha escolhido, aquilo que não posso evitar nem desprezar porque é o modo como fui concebido e trazido ao mundo. ${ }^{20}$ (CISNEROS, 2015, VI, p. 02, tradução livre nossa)

Ademais, segundo o narrador, o romance também pode ser lido como um meio para dar oficialidade ao casamento dos pais e as convenções que precisaram enfrentar desde os anos de 1970 para viver o amor, assim como as gerações anteriores:

[...] E porque também preciso que Cecilia Zaldívar, minha mãe, reconheça e entenda que os papeis não me importam e nunca importaram [...] como antes tampouco importaram para Nicolasa, Carolina e Esperança, e que saiba que este livro talvez possa ser o documento que todas buscaram, que estas páginas são os únicos papéis que importam. Aqui a história de todas elas, ou a minha versão das histórias de todas, está a salvo. Este romance é a ata perdida do matrimônio de meus pais. ${ }^{21}$ (CISNEROS, 2015, VI, p. 12, tradução livre nossa)

A(s) memória(s) e o seu relato, portanto, servem como uma (re)escrita destas experiências vividas e propiciam outros significados em seu tempo presente. Outra vez o romance evidencia que a narrativa e a(s) (re)construções destas memórias individuais e familiares, públicas e privadas são discursos

\footnotetext{
20 Texto original: "[...] esas palabras, digo, son mi abolengo, son parte de mi patrimonio directamente, porque nombran aquello que me toca, que está en mí sin que yo la haya elegido, aquello que no puedo escapar ni desentenderme porque ha nutrido y elaborado mi presencia en el mundo" (CISNEROS, 20215, VI, p. 02).

${ }_{21}$ Texto original: "[...] Y porque además necesito que Cecilia Zaldívar, mi madre, asuma o entienda que los papeles no me importan ni me importaron nunca [...] como antes tampoco los necesitaron Nicolasa ni Carolina ni Esperanza, y que sepa que este libro quizá sea el documento que todas ellas buscaban, que estas páginas son los únicos papeles que importan. Aquí la historia de todas ellas, o mi versión de las historias de todas ellas, está a salvo. Esta novela es un acta de matrimonio perdida de mis padres" (CISNEROS, 2015, VI, p. 12).
} 
elaborados no tempo e no espaço por distintos sujeitos e podem ser lidos de maneiras variadas porque são linguagem, isto é, tratam-se de versões. De modo mais preciso, não há nada inacabado e imutável nestas experiências narradas, sendo La distancia que nos separa o relato editado de sua versão destas vivências.

Consciente que a(s) memória(s) - e por consequência o próprio relato - é linguagem, o narrador surpreende-se durante o processo de conhecimento da figura de seu pai que no exercício da escrita era um sujeito distinto do comportamento com a família. Neste contexto familiar, sobretudo com os filhos homens, o pai se fazia presente de modo rude e disciplinar, tal qual em suas condutas na posição militar que ocupou:

Um Gaucho que não se parecia ao Gaucho que tive como pai, um homem já nos seus cinquenta anos, paralisado, austero, difícil de compreender. [...] Não é a mesma coisa ser criado por um tenente coronel que por um general da Divisão..$^{22}$ (CISNEROS, 2015, III, p. 24, tradução livre nossa)

Contudo, é na leitura do narrador das cartas de Fernán Cisneros (bisavô de Renato) ao filho e a esposa Esperanza sobre o jovem, bem como nas missivas trocadas entre el Gaucho com sua namorada e comprometida Beatriz Abdulá, que há a descoberta que Luis Federico Cisneros Vizquerra foi um adolescente indisciplinado e um jovem apaixonado. Ao ser transferido para o Peru nos anos de 1940, vendo-se obrigado a deixar Beatriz e adiar seu compromisso de matrimônio, o jovem militar solicita à instituição do exército que possa honrar a relação com Beatriz. O exército nega o pedido e, o que se destaca nesta passagem sobre a vida do pai que o narrador desconhecia, é a percepção de um sujeito distinto do que conhecia como pai, chefe de família e militar. Também foi em

22 Texto original: "[...] Un Gaucho que no se parecía al Gaucho que yo tuve como padre: un hombre ya en sus cincuenta, cuajado, duro, difícil de penetrar. [...] No es lo mismo ser criado por un teniente coronel que por un general de División" (CISNEROS, 2015, III, p. 24). 
cartas com o filho Renato Cisneros que o pai se expressou de modo mais próximo ao sujeito que descobriu nestes outros textos:

Existem pessoas que somente podem expressar seus sentimentos por escrito. Meu pai era deste conjunto humano: para ele as palavras eram lugar do afeto, a região onde os sentimentos ocultos no cotidiano apareciam e exigiam forma. Nestas cartas era ele de verdade, ou assim eu o via. Escrevia o que não me dizia, o que não podia dizer-me diante dos outros, como na sala de jantar ou em outros cômodos. Nesta privacidade das cartas era meu amigo, em público nem tanto. ${ }^{23}$ (CISNEROS, 2015, III, p. 06, tradução livre nossa)

Atentar para este sujeito verbal escrito diferente do sujeito familiar, militar e público é significativo para apreender a dimensão ampla que o relato memorialístico alcança no romance. Isto é, estas revelações do filho também nos permitem pensar que o uso da linguagem em instâncias particulares nos torna seres flexíveis, isto é, somos flutuantes em nossas relações sociais e íntimas. Para além, assim como propõe Paul Ricouer, não podemos ignorar que neste relato em específico trata-se de memória(s) também sob o âmbito da percepção (aquilo que se apreende do narrado) e da imaginação (autoficção):

[...] Portanto, é também como forma mista que é preciso falar da função da imaginação, que consiste em "pôr os olhos", função que podemos chamar ostensiva, que mostra, que expõe, que deixa ver. (RICOUER, 2017, p. 70, grifos da obra)

Tal proposição nos permite ler que o narrador faz uma escolha neste seu relato sobre a figura do pai que também é a controversa figura pública: não adentra criticamente no campo da sua atuação militar durante os anos conturbados no Peru. Apesar de referendar estes episódios da história nacional,

23 Texto original: "Hay personas que solo pueden expresar sus sentimientos por escrito. Mi padre era de ese conjunto de personas: para él las palabras eran lugar del afecto, la región donde los sentimientos anulados del día a día aparecían y cobraban forma. En esas cartas era él de verdad, o así lo veía yo. Escribía lo que no me decía, lo que no podía decirme delante del resto, en el comedor o en la sala. En la privacidad de esas cartas era mi amigo, en público no tanto" (CISNEROS, 2015, III, p. 06). 
apresentando um militar visto por seus companheiros de carreira por diferentes ângulos, o narrador Cisneros não ousa aprofundar-se nestas polêmicas. Talvez, como ele próprio argumenta ao longo do romance, para não trair sua família e, também, porque não consegue se desvencilhar de um olhar comprometido uma vez que a figura de seu pai e o militar constituem o mesmo sujeito. Em todo caso, para um relato memorialístico que reiteradamente expõe a intenção de exumar o cadáver de Luis Federico Cisneros Vizquerra, claramente há um pêndulo para a escrita da história privada e individual do Gaucho Cisneros.

\section{CONSIDERAÇÕES FINAIS}

Em nossa proposição de leitura, o romance La distancia que nos separa é uma narrativa de memória familiar que dialoga com uma das tendências da narrativa hispano-americana dos últimos decênios: questiona o discurso oficial da história e, também, a própria ideia de linguagem. Autoproclamada como uma autoficção, o relato memorialístico de Renato Cisneros engendra uma difícil empreitada discursiva, na medida em que transita entre associações móveis, abertas, sujeitas a reinterpretações. Neste sentido, tanto o tempo presente (que é o da escrita do romance) como o tempo passado que (re)constrói estão sob a égide das incertezas e, desta forma, a matéria narrada não é uma mera reiteração de experiências vividas e compartilhadas no tempo e no espaço da família Cisneros, seu círculo de relações e a vida pública. Ao contrário, o romance explicita que o que se narra permanece sob o jugo de leituras constantes, tanto porque os sujeitos que leem o relato são indivíduos com perspectivas próprias, como pelo fato de que a vida segue seu curso (e pode oferecer outras dimensões sobre o narrado), e, sobretudo, porque o romance e a(s) memória(s) tratam-se de linguagem. A empreitada da busca pela figura do pai em La distancia que nos separa também descortina uma discussão sobre a identidade que se constitui como múltipla e aberta. Apesar de 
fazer uma clara opção em não discutir a fundo a problemática figura pública militar El Gaucho Cisneros, interpretamos que este é um dos mais complexos e significativos romances do cenário peruano dos últimos anos.

\section{REFERÊNCIAS}

AÍNSA, Fernando. Palabras Nómadas. Nueva Cartografía de la pertinencia. Madrid: Iberoamericana/Vervuet, 2012. [E-Book]

ATANASIO, Angelo. Renato Cisneros: "Me interesaba despertar en aquellos que tienen tantas certezas sobre su relato familiar algunas dudas incómodas". BBC/New/Mundo. Entrevista. 24 de janeiro de 2018. Disponível em: [https://www.bbc.com/mundo/noticias-42750503]. Acesso em: 30/03/2021.

CISNEROS, Renato. La distancia que nos separa. Perú: Planeta, 2015. [E-Book]

DE VIVANCO, Lucero. "Pares díspares": dinámicas de simbolización de la violencia política en la literatura peruana (de 1980 al presente). Memorias en tinta. Ensayos sobre la representación de la violencia política en Argentina, Chile y Perú. Chile: Ediciones Universidad Alberto Hurtado, 2013, p.5718-6168. [E-Book]

MAIOLI, Juliana Bevilacqua. Identidades transnacionais na narrativa hispano-americana contemporânea: uma leitura de Árbol de familia, de María Rosa Lojo, e Una vez Argentina, de Andrés Neuman. Polifonia, Cuiabá-MT, vol.27, n.47, p. 55 a 76, jul.-set., 2020.

RICOUER, Paul. A memória, a história, o esquecimento. Tradução de Alain François (et al). Campinas, São Paulo: Editora da Unicamp, 2007.

RICOUER, Paul. Tempo e narrativa. A intriga e a narrativa histórica. Tradução de Cláudia Beliner. São Paulo: Editora Martins Fonte, 2010.

SARLO, Beatriz. Tiempo pasado. Cultura de la memoria y giro subjetivo. Una discusión. Buenos Aires: Siglo XXI Editora Argentina, 2007.

VARIKAS, Eleni. A escória do mundo: figuras do pária. Tradução de Nair Fonseca e João Alexandre Peschanski. São Paulo: Editora Unesp, 2014.

VELÁZQUEZ, Noberto Barreto. La Operación Cóndor: un enfoque comparativo. Historica, s.d., XXXVII, vol.2, p. 171 a 178, 2013.

Nota do editor:

Artigo submetido para avaliação em: 31 de março de 2021.

Aprovado em sistema duplo cego em: 27 de julho de 2021. 